\title{
The Professionalization of Philosophy and the Criteria of Philosophical Knowledge
}

\author{
Vera Tripodi \\ University of Turin \\ vera.tripodi@unito.it
}

\begin{abstract}
In this paper, I investigate the issue of the professionalization of philosophy, taking as my starting point the debate triggered by the publication of Diego Marconi's monograph, Il mestiere di pensare (Thinking as a Trade, 2014). This debate about the state of the art of Italian philosophy and the increased tendency towards specialization in philosophy is still on-going. It raises the issue of how to understand the putative split between analytic and continental philosophy, and how to establish standards or criteria for evaluating the quality of philosophical research. I conclude by posing the question about what needs to change in our knowledge practices and suggest that what is needed is an overhauling of our conceptions of trust, reliance, testimony, and justice, with a view to re-defining how social identity affects the way we operate in philosophical practice and how we establish our credibility.
\end{abstract}

\section{Keywords}

specialization in philosophy - professionalization of academia - biased notions epistemic injustice

Recently, there has been increased debate in the Italian academia about the cultural effects of the professionalization of philosophy and the opposition of professional philosophers and media-oriented philosophers. This discussion started with the publication of the volume Il mestiere di pensare (Thinking as a Trade, 2014) by Diego Marconi. This on-going debate about the state of the art of Italian philosophy and the increased tendency towards specialization in philosophy raises the issues of the putative split between analytic and continental 
philosophy, about philosophy in general, and how to establish standards or criteria for evaluating the quality of philosophical research. This paper is divided in two parts. In the first, I will investigate the issue of the professionalization of philosophy by taking Marconi's arguments as a starting point. In the second part, I outline the limits of the professionalization of academia, and put forward ideas on how philosophy can move forward, in Italy and elsewhere.

The Professionalism of Philosophy

What is philosophy today? And what is it for? Philosophy once played an important role in the societies and the politics of many Western countries. Traditionally, according to ancient philosophers, the philosophical examination of life is something that makes human beings virtuous. On this view, philosophy is thought as a kind of activity that can directly influence human action. This view is connected with Socrates' perspective about the sense of philosophical practice, namely that an unexamined life is not worth living. Here the underlying idea seems to be simple enough: the intellectual quest for wisdom and knowledge improves human existence. This also matches with what the majority of ordinary well-educated people believe philosophy is or should be. More precisely, most people think that wisdom is the original goal of philosophy and that a philosopher should devote his (or her) life to the asking of questions (trying to find answers) about the most basic and universal issues: the nature of what it is to be human, the nature of God, mind and reality, the value of existence and its meaning, or of the good life and justice.

There has certainly been a great increase in technicality in recent philosophy. Ancient and modern philosophers seem, one might say, to lack the current essential academic professionalism. Few contemporary philosophers show much inclination to approach the general public with their subject and to disseminate their discipline. Rather, most of them present what they do as something exclusive or elitist, namely something in which outsiders cannot participate. Nowadays, the nature of the relevant philosophical expertise does not seem to be very clear to those outside the field. In fact, there is a tendency of its practitioners to require a kind of technicality, which might impress outsiders without necessarily producing in them a wish to join in.

If it is so, we need to ask: is it desirable to replicate the classic ideal according to which the value of philosophy in the end lies in itself and what it does for human thought and life? Might one expect Aristotle or Descartes to value the present state of things in philosophy? Should we criticize the narrowness of many present-day conceptions of philosophy and its separation from the 
pursuit of the nature of the natural sciences? Might philosophy be returning to its original and practical purposes?

Philosophy has become a purely academic discipline over the last few centuries and philosophers have been gradually dissociated from the amateurs. Moreover, the number of people involved in the subject is higher now than it has been at any time in the past years. The issue of professionalism of philosophy can be couched in the following question: does the subject-matter of philosophy demand for its practices a form of professionalism and does philosophical progress depend upon its practices within academic institutions? The institutionalization of philosophy and its professionalization in the academic setting is, as David W. Hamlyn has argued in his book Being a Philosopher, ${ }^{1}$ an answer to the postmodern negation of the meaning of philosophy: that is, the idea that philosophy as a discipline is in crisis and that its end - and that of its institutions - is approaching. According to Hamlyn, philosophy today should be considered a practice. Therefore, the history of philosophical practice should be seen as associated with the social context and the way in which philosophy has been developed and has become the academic profession it is today. More precisely, the philosophical practice is concerned with (and reflects) the way in which the discipline has been discussed and examined through arguments, debates, philosophical institutions, publications in scientific peer-reviewed journals or books, teaching, associations of philosophers, congresses, seminars, and universities. Accordingly, philosophy no longer has its place outside academia or scientific institutions. But, what does "specialization" in philosophy or "being a professional philosopher" mean? This question will be the topic of the next paragraph.

\section{Specialization in Philosophy}

Since the very beginning, philosophy has always been characterized as a kind of writing. ${ }^{2}$ Unlike in the past, philosophy today is no longer an activity practiced by a few wise persons; rather it is carried on by thousands of professionals in the entire world. For starting a carrier and getting a position in academia, normally a bachelor and doctoral degree are required. But, in many cases, this is not enough for becoming a professional philosopher. It is essential also to have the interest, the ability, and dedication to pursuing this discipline. As is the case in other disciplines, the professionalization in philosophy brings with

1 D. W. Hamlyn, Being a Philosopher: The History of a Practice (London: Routledge, 1992).

2 D. Marconi, Il mestiere di pensare (Torino: Einaudi, 2014). 
it an intense specialization. For this reason, it is essential for the profile of the philosopher and his (or her) career to publish books and articles of quality. As a consequence, the number of publications in philosophy has increased enormously over the years. Therefore, a professional philosopher cannot (seriously) follow all philosophical research available to the generic public but only those that professionals belonging to his (or her) community think, deserve more attention. Thus, according to Marconi, specialization is imposed by the proliferation of scientific publications: a philosopher simply cannot read or study all the articles and books about philosophy written and published. Rather, as is the case in other disciplines, such as mathematics or biology, he (or she) has to restrict - if he (or she) aims to do high quality research - his/her the attention to (and focus on) the publications concerning a specific scientific area of the discipline. ${ }^{3}$

Specialization certainly is not the only possible choice, but the available alternatives are not brilliant. ${ }^{4}$ Among the alternatives to specialization, Marconi says, there are amateurism (the demand of contributing to the growth of knowledge without taking into account the work of other scholars) and thematic inventiveness (the search for non-obvious relations between authors, themes and problems that seem to be distant or for uncommon research subjects).

Let us consider more precisely the two alternatives. The first is, Marconi maintains, doomed to frustration. The amateur, who deals with some philosophical topics by not taking into consideration the specialist bibliographies, risks ignoring important objections or repeat argumentations that have already been well developed. In fact, only few extraordinary personalities - like, for example, Ludwig Wittgenstein - have made important progress and a contribution to philosophy by working alone. ${ }^{5}$

The second alternative might be risky. When brilliant scholars embrace this attitude, innovative research can be produced and a profound contribution to the field could be the result. A good example of this is A Nice Derangement of Epitaphs by Donald Davison, a paper devoted to malapropisms. However, Marconi argues, when this attitude is embraced by scholars who are not so brilliant, it is hazardous: those who choose as a topic like "Dante and the computer" might not understand everything about Dante or computers (or about both issues), with the result that they might produce works that fall within the so-called category of bullshit. ${ }^{6}$ The goal in such cases is to produce something

\footnotetext{
3 Marconi (2014), 13.

4 Marconi (2014), 13.

5 Marconi (2014), 14.

6 Marconi (2014), 14.
} 
that will have a profound effect on the generic audience who is not a competent audience.

Otherwise, Marconi argues, specialization has the advantage of allowing (not necessarily extraordinary) scholars to do honest and reasonable research and, consequently, to increase the amount of honest and reasonable philosophical knowledge. Being a specialist philosopher means focusing one's own research on a small area of the discipline, for example, only on Kant and the reception of The Critique of Pure Reason, or on the philosophy of mind and the issue of "consciousness", and so on. Dealing seriously with specific disciplinary topics requires a lot of effort, but one can make it. For doing that, the relevant literature is manageable and the required skills are acquired in reasonable time. Instead, taking care of philosophy to court an audience is simply impossible today. The same goes for other disciplines. No one deals with physics or biology except in the sense that he or she handles a specific research area that falls within physics or biology; similarly, those who are engaged seriously in philosophy work on authors or problems whose studies are considered part of philosophy. Marconi defends the professionalism of philosophical practise by analysing the risks of this tendency and proposing some remedies to counter its negative consequences. Let us see in more details what these risks are.

The Consequences of Philosophical Professionalization

What is central to Marconi's account are the two main consequences of philosophical professionalization. A first consequence is, Marconi contends, that most of what philosophers write may be understood by only a few specialists. A second consequence of the professionalization is that - in philosophy as in the natural sciences and mathematics, but also in the social sciences - many philosophers seem to deal with minute problems and issues relating to their research program, of which well-educated people can have only an approximate idea in the matter of detail. Does this mean that, Marconi asks, philosophy has given up on the answer to life's big questions, which were - according to the very widespread image - the exact raison d'être of philosophy? Has philosophy also given up what seems to be its vocation, speaking to all humans? Does it follow that this kind of specialization and technicality is in contradiction of the very nature of philosophy?

It should be noted that, Marconi highlights, the specialist choice is not universally shared among those who are professional philosophers. Moreover, it is not at all obvious that philosophy can afford the specialist choice. Philosophy, one might argue, still has a generalist vocation. Specialization, into which 
philosophy seems be forced today, constitutes a problem not easily overcome since its survival depends on it. Moreover, Marconi emphasises, specialization does not imply either conformism or stasis. ${ }^{7}$

Yet, specialization is not the only consequences of the philosophical proliferation. Another consequence is the deep transformation of the image of the philosopher. ${ }^{8}$ Until the 1930's, philosophers had taken charge of the task of providing an overall picture of reality, able to give an account of various aspects of human existence in the world: morality, religion, law, economics, politics, art and science. On this account, each philosopher had the task of being and becoming a Great Philosopher (as Kant or Hegel were). The Great Philosopher was a genius, able to produce a convincing and original synthesis that is entirely "new" because the result of a unique vision.

This picture changed when philosophers increased in number, from only a few to several hundred and then - in a short time - several thousand. Thus, the problem was to find a way to make philosophy an activity for scholars, who might be even well-educated and intelligent but not necessarily brilliant or original. Since the end of the twentieth century, various solutions to this problem were conceived.

Marconi recognizes four solutions. ${ }^{9}$ The first solution, proposed in the second half of the nineteenth century, was that of a philosophical "return to Kant". For neo-Kantian philosophers, it was not a matter of devising new systems but of understanding, applying and possibly integrating the philosophy of Kant, considered as the best philosophy that had been produced in the modern age. A second solution, elaborated during the same period, was "history of philosophy". This solution was strictly connected to the Hegelian project. The history of philosophy could be the reconstruction of the thought of philosophers, the clarification of their relations, and the study of their genesis and so on. This task was within reach of many philosophers. To carry out this task, it was not required to have an encyclopaedic knowledge or to be a talented philosopher. In addition, this choice is not offered as theoretical research. A third solution was "hermeneutics", in the version offered by Hans Georg Gadamer, and thought as a way of doing philosophy through the relationship with the Western philosophical tradition. Let us suppose, for example, that a hermeneutic philosopher is interested in philosophy of mind. If it is so, he or she will not address some of the most fundamental and difficult questions there are, such as for example whether mind is identical to brain or whether mental properties

\footnotetext{
7 Marconi (2014), 17.

8 Marconi (2014), 17-18.

9 Marconi (2014), 19-21.
} 
supervene on brain properties. Rather, he (or she) will try to describe the formation of the current concept of "mind" and "mental", by reconstructing the historical and cultural material, in which he (or she) will focus on certain events rather than on others, on certain philosophers (writers or poets) rather than others. Unlike the hermeneutic option, this solution is conducted as theoretical research. The last solution to the philosophical proliferation is offered by "analytic philosophy". Analytic philosophers deal with, Marconi claims, philosophical problems. In doing this, they do not describe or grasp the historical and cultural meaning of a philosophical problem; rather they try to solve that problem alone. Certainly, there is genuine disagreement among analytic philosophers about what a philosophical problem is: some of them believe that a philosophical problem can be solved by making it disappear (by showing, for example, that it arises from the fact that ordinary language is vague and misleading); others think that a philosophical problem can be solved in the same way we solve certain scientific problems, that is, by elaborating theories that describe adequately the phenomena that are problematic. The point, moreover, is that analytic philosophers are interested in a philosophical problem in its current form, that is, in the formulation they have received from the philosophical researches in the last decades. Analytic philosophers are not interested in the past history of problems. Thus, analytic philosophy is a reflective activity, based on argumentative reasoning continuously monitored and subject to the control of the philosophical community. For an analytical philosopher, it does not make sense to present theories already known, or reject objections already articulated. The argumentative quality is more intersubjective than the persuasiveness of an interpretation. According to Marconi, these aspects of analytic philosophy show why this philosophical approach is the more common (maybe the best, he seems to suggest) solution to the philosophical proliferation. Analytic philosophy allows a researcher to delimit, as he or she prefers, his or her research area. Thus, the analytical philosopher no longer has the task of producing a comprehensive view of things, but can - as a professional - try to make his or her contribution to the solution of a problem on which other philosophers are also working. Analytic philosophy is, Marconi claims, the paradigm of the artisan conception of philosophy: ${ }^{10}$ the vision according to which philosophy is seen as an honest trade, an activity not reserved for geniuses but open to many people of some intelligence, culture and creativity. It seems therefore that, Marconi concludes, this conception is the most suitable version of philosophy in a context in which professional philosophers currently count some tens of thousands. 
For the most part, I genuinely agree with the brilliant analysis Marconi makes of the phenomenon at issue here. In what follows, I will be focusing on some limits of the criteria endorsed by the philosophical community for evaluating the quality of philosophical research. I suggest that to tackle the issue of professionalization in academia is also to tackle the issues of how criteria affect the way we operate in philosophical practices and how we establish our credibility or how we come (or fail to come) to exercise authority in philosophy.

\section{Some Limits of the Criteria for Evaluating the Quality of Philosophical Research}

The professionalization in academia is - I guess - closely linked to the issue of methodology and to the phenomenon of discrimination in philosophy. When we discuss professionalization in philosophy, I believe, the questions we need to ask are the following: what does it mean to be a good philosopher or to be competent in philosophy? What (and who) does determine the philosophical competence? Can some features of philosophy as a discipline - such as some of its argumentative models and methods or the nature of the themes considered valid - be inherently discriminatory? Moreover, can philosophical method be a vehicle for a form of injustice? Can our philosophical practices marginalize and discriminate against some people? And if this is the case, in which context?

To make clear the position I am about to propose here and to dispel any doubts about it, it is useful to define more precisely about what I mean by discrimination. I think we can make a distinction between two forms of discrimination in philosophy. The first form might be called disciplinary discrimination or methodology discrimination. One may say, in fact, that this kind of discrimination might be legitimate if we determine that there is a scientific authority we delegate to our idea of philosophy as a disciplinary unit. In other words, this kind of discrimination has to do with the fact that professional philosophers in academia and referees in scientific journals act as gatekeepers, that is, a sort of selective authority, and this has an effect on the agenda of the discipline. These gatekeepers, choosing important research topics and criteria for evaluating quality, play a legitimate role in establishing what good philosophy or a good contribution to the discipline is. By contrast, the second form of discrimination should be understood as based on bias, something that has to do, for example, with the phenomenon of epistemic injustice or with the (frequently) unacknowledged role of some social categories (such as women or minorities) in our departments and in our discipline. 
These forms of discrimination should be separated. Nevertheless, I suggest, it seems to me that they are connected on another level. The first form of discrimination is linked with the issue of whether the criteria of scientific merit in itself is legitimate or not. If it is illegitimate, considerations about the scientific merit necessarily lead to forms of non-legitimate discrimination. By contrast, if the policy about the evaluation criteria is legitimate, some forms of discrimination are legitimate; others might not be legitimate because of how the criteria are applied. If it is so, here the problem is not the scientific merit, but the bias in the application of the principles for measuring scientific merit. Therefore, the question at issue here deals essentially with two concerns regarding the topic of philosophy and marginalization: methodological aspects and normative aspects.

Let us consider first the normative aspects of the link between philosophy and marginalization. As Sally Haslanger ${ }^{11}$ has shown, being a good philosopher is in part a social issue. The category of philosopher is socially constructed. According to her, philosophers are constructed as kinds of people. Specifically, our notion of being a philosopher and the norms associated to this social identity are socially constructed. This does not mean simply that social forces influence this notion. In order to be a philosopher, one has to satisfy certain relational properties: for example, being part of a network that an institution (e.g. a university) provides. Being recognized as a philosopher has to do with how one is viewed and treated in a philosophical community. Still, one is a philosopher by virtue of standing in a certain relation to others in a particular social context, and the philosopher's role is situated within a complex social system. To become a philosopher means to satisfy the norms which function in this role, and this depends on contextual factors. In contexts where the norms of 'being a good philosopher' function as a serious model of evaluation and of selection, it is a common belief that philosophical behaviour is the result of certain traits and capacities that are the real basis for the evaluation. Being a good philosopher means, in part, acting in a certain way. Certain norms fix, namely, what is to be like a good philosopher working in academia: getting research articles published in professional journals and presenting them at conferences, being intellectually acute, performing well during a talk, showing evidence of excellence in teaching, being invited as speaker to international meeting, to name a few. Also, in the Western philosophical scenario, only those who act as good philosophers receive the approval of academia. Furthermore,

11 S. Haslanger, 'Gender and Race: (What) Are They? (What) Do We Want Them To Be?', Noûs 34 (1)(2000): 31-55; S. Haslanger, 'Changing the Ideology and Culture of Philosophy: Not by Reason (Alone)', Hypatia 23 (2)(2008): 210-223. 
a norm is appropriate to a role when «satisfying [it] would make for, significantly contribute to, success in that role». ${ }^{12}$ Norms are relational, contextually sensitive and grounded in social relations. Philosophical norms are norms taken to be appropriate for a philosopher. On the basis of these norms, the philosophical community considers certain performances in this role as good and others as not.

Let us go back now to the issue mentioned above on the methodological aspects about discrimination in philosophy. As various feminist epistemologists and philosophers of science have argued, our practices of knowledge attribution, acquisition, and justification can systematically disadvantage some people, in particular women and other subordinated groups. Dominant knowledge practices can in fact discriminate against some individuals in different ways: by excluding them from inquiry; denying them epistemic authority, denigrating their modes of knowledge; producing theories that portray them as inferior, deviant; producing social theories that make gendered power relations invisible; reinforcing gender bias and social hierarchies. ${ }^{13}$ Moreover, many feminists agree, most canonical philosophical notions require critical analysis to uncover (gender or race) bias. Certainty, the issue of how to define a biased notion is a disputed topic within feminist philosophy: feminists may mean different things by 'biased' notions or concepts. All these forms of marginalization are linked, I will argue, to the phenomenon of the epistemic injustice. Before doing that, I will focus first on what a gendered notion in philosophy might be.

According to Charlotte Witt, for example, we should distinguish between intrinsically and extrinsically gendered notions. On this distinction, an intrinsically gendered notion "is one that necessarily carries implications regarding gender", ${ }^{14}$ namely, it is a "notion that is connected with gender and sexual difference". ${ }^{15}$ Several feminist philosophers have argued, for example, that Aristotle's notions of 'form' and 'matter' reflect sexual differences: the former is intrinsically connected with 'being male', and the latter with 'being female.16

\footnotetext{
12 Haslanger (2008), 219.

13 C. Townley, A Defense of Ignorance: Its Value for Knowers and Roles in Feminist and Social Epistemologies (Plymouth: Lexington Books, 2011).

14 C. Witt, 'Feminist History of Philosophy'. In The Stanford Encyclopaedia of Philosophy, ed. E. N. Zalta (URL = http://plato.stanford.edu/entries/feminism-femhist/, 2007).

15 Witt (2007).

16 Cynthia Freeland writes: "Aristotle says that the courage of a man lies in commanding, a woman's lies in obeying; that 'matter yearns for form, as the female for the male and the ugly for the beautiful;' that women have fewer teeth than men; that a female is an incomplete male or 'as it were, a deformity': which contributes only matter and not form
} 
This gender association between form and matter raises problems for feminists. As is well known, Aristotelian matter and form are not treated as equal. Form has priority over matter: while 'matter' is the undifferentiated primal element out of which all things are made, form is the 'whatness' of a thing, 'the essence of each thing, and its primary substance. Thus, the theoretical gender bias is - some feminists conclude - intrinsic to the Aristotelian distinction between form and matter, and the gender associations in it are not removable.

By contrast, an extrinsically gendered notion "typically does carry implications concerning gender, but not necessarily so". ${ }^{17}$ According to some feminist philosophers, for example, the Aristotelian distinction between 'form' and 'matter' is not intrinsically connected with gender differences or necessarily implicated in the rest of Aristotle's theory. Actually, Aristotle's texts are misogynist but not all his views are biased against women. Most of his views are not necessarily connected to what he says about women and, consequently, not all of them should be rejected. Thus, it is plausible to argue that we should ignore his considerations on women simply as false and mistaken but consider other theses of his as valuable for philosophy and feminist purposes. ${ }^{18}$

Let us see now in which sense these form of marginalization are linked to the phenomenon of the epistemic injustice. Introduced by Miranda Fricker, ${ }^{19}$ the concept of epistemic injustice refers to distinctively epistemic forms of injustice and relates to inequalities of social power. According to Fricker, such an injustice occurs when a hearer makes unfair judgments about the credibility of a speaker (or a group of individuals) as a giver of knowledge. More precisely, it is a kind of injustice in which someone is judged unfairly specifically in his or her capacity as an expert and informant. As many authors maintain, a person's capacity for knowledge is essential to human value. Thus, when this is unfairly undermined, the person suffers an intrinsic injustice and is deprived

to the generation of offspring; that in general 'a woman is perhaps an inferior being'; that female characters in a tragedy will be inappropriate if they are too brave or too clever". See C. Freeland, 'Nourishing Speculation: A Feminist Reading of Aristotelian Science', in Engendering Origins: Critical Feminist Readings in Plato and Aristotle ed. Bat-Ami Bar On (Albany: State University of New York Press, 1994), 145-46.

17 Witt (2007).

18 C. Witt, 'Feminist Interpretations of the Philosophical Canon', Signs: Journal of Women in Culture and Society, (31) (2) (2006): 537-552. Martha Nussbaum, for example, believes that Aristotle's ethical ideal is valuable.

19 M. Fricker, Epistemic Injustice: Power and the Ethics of Knowing (Oxford: University Press, 2007). 
of a fundamental element of respect. According to Fricker, ${ }^{20}$ it is possible to distinguish between two forms of epistemic injustice: testimonial and hermeneutical. The epistemic injustice is testimonial when our credibility is downgraded (by prejudice, gender or race); and hermeneutical when, in trying to make sense of our social experiences, we are left at an unfair disadvantage by a void in the interpretative resources available in our community.

In order to explain how this kind of injustice might be deeply embedded in academia and in research valuation practices, consider for example the case of a woman philosopher. What kind of a problem is the denial of a woman as expert? As Jennifer Saul ${ }^{21}$ has shown, many women have problems in being identified as experts and have trouble being heard or taken seriously.

As many philosophers maintain, it transpires that women belong to a social category that is systematically excluded from some realms of epistemic activity. This not only causes social or political harm, but also produces a form of epistemic harm and disadvantage. For example, according to many canonical philosophers, women are inferior to men, ${ }^{22}$ and thus men are widely portrayed as more competitive than women, while women are seen as more nurturing than men; women and men communicate and think very differently; women regulate their actions by arbitrary inclinations and opinions, men use reason and logic to solve problems. Moreover, it is often argued that women are irrational because they are guided by feeling (not by reason) and are therefore unsuited to activities such as science. In addition, the philosophical tradition has, implicitly or explicitly, provided a negative characterisation of 'woman' and of the 'feminine'. Moreover, There is significant research indicating that people are affected by implicit bias, some of which relates to gender and sex. Gender bias affects the way we judge the quality of a woman's work, speech, testimony and views. It shapes our expectations about men and women's performance: for example, people believe that girls are poor at math; men's achievements tend to be rated more highly than women's; and women's work is evaluated more negatively than it deserves. As this research shows, culturally we consider originality, excellence, leadership, intellectual ability as masculine traits and consequently associate these traits more with men than women. Of course, a

$20 \quad$ Fricker (2007), 1.

21 J. Saul, 'Implicit Bias, Stereotype Threat and Women in Philosophy', in Women in Philosophy: What Needs to Change? eds. F. Jenkins, K. Hutchison (Oxford: Oxford University Press, 2013) 39-6o.

22 A. E. Cudd, 'Missionary Positions', Hypatia: A Journal of Feminist Philosophy 20 (4) (2005): 164-182. 
woman may herself be implicitly biased and convinced that some traits are more typical of males, and even those who hold egalitarian beliefs may also have implicit bias. ${ }^{23}$

The absence of women from the canonical philosophical tradition is the upshot of this. In the context of Western culture, certain intellectual activities like philosophy (and science) are still viewed as exclusively male, and women remain seriously under-represented in the discipline and in philosophy departments. ${ }^{24}$ These are often environments in which women do not feel comfortable, few women achieve high academic positions, and academic authorities often automatically consider men as preferable candidates for positions of responsibility. In such a context, it is plausible to think of women as victims of epistemic injustice: they may feel uncomfortable; may become convinced they are not good at philosophy; they may drop out of philosophy classes or abandon the idea of a career in academia. ${ }^{25}$ As a result, some philosophical contexts undermine women's performance because, in a context in which the common prejudice is that women are not well equipped for philosophy, a woman is not able to perform just as well as a man or produce her best work. ${ }^{26}$

Can we remedy these forms of injustice?27 What needs to change in our knowledge practices? ${ }^{28}$ To my mind, the concept of knowledge should be considered in connection with notions such as trust, reliance, testimony, and justice. Moreover, we need to re-imagine what 'authority', 'credibility' or 'testimony' are, and revisit the ways in which we measure quality, ability, credibility and reliability. What we need to do is challenge the narrowness of what is understood as 'philosophical knowledge' and what constitutes 'good knowledge'. My idea is that we should address such and similar issues, by exploring (i) how

23 Saul (2013), 55 .

24 Antony, L., 'Different Voices or Perfect Storm: Why are there so few Women in Philosophy?', Journal of Social Philosophy 43 (3) (2012): 227-255; Valian, V., Why so slow? The advancement of women (Cambridge (MA): The M.I.T. Press, 1998).

25 Steele, C. M., Whistling Vivaldi: How Stereotypes Affect Us and What We Can Do, (New York: W.W. Norton, 2010); Steele, C. M., Aronson, J., 'Stereotype threat and the intellectual test performance of African Americans', Journal of Personality and Social Psychology (69) (1995): 797-811.

26 Tripodi, V., 'Intuition, Gender and the Under-representation of Women in Philosophy', Rivista di Estetica (58) (1)(2015): 134-144.

27 Anderson, E., 'Epistemic Justice as a Virtue of Social Institutions', Social Epistemology 26 (2) (2012): 163-73.

28 Valian, V., 'Beyond gender schemas: Improving the advancement of women in academia', Hypatia (20) (2005): 198-213. 
social identity affects the way we operate in philosophical practice and how we establish our credibility or come (or fail to come) to exercise authority; and (ii) what we should do in order to promote diversity and pluralism in knowledge.

In my analysis, I took my cue from Marconi's reflections about the professionalization of philosophy in Italian academia. In doing that, I took the case of women in academia as an example of how discrimination might occur in philosophy and in our departments. Certainly, this kind of discrimination does not affect just women and it does not take place only in the Italian context. Instead, I argue, everyone might be affected negatively when his or her capacity to claim recognition as a conveyer of knowledge is dismissed. This phenomenon has its roots in part, in the collective institutional and social policies held in place by what we frequently accept as tacitly justified practice for evaluating the quality of philosophical research. I truly believe that improvements are imperative if the philosophical community (in Italy and elsewhere) wants to be faithful to the democratic ideal of a community led by principles of rigorous critical and fair evaluation.

\section{References}

Anderson, E., 2012, 'Epistemic Justice as a Virtue of Social Institutions', Social Epistemology 26 (2): 163-73.

Antony, L., 2012, 'Different Voices or Perfect Storm: Why are there so few Women in Philosophy?', Journal of Social Philosophy 43 (3): 227-255.

Cudd, A. E., 2005, 'Missionary Positions', Hypatia: A Journal of Feminist Philosophy 20 (4): 164-182.

Freeland, C., 1994, 'Nourishing Speculation: A Feminist Reading of Aristotelian Science', in Engendering Origins: Critical Feminist Readings in Plato and Aristotle ed. Bat-Ami Bar On (Albany: State University of New York Press), 145-46.

Fricker, M., 2007, Epistemic Injustice: Power and the Ethics of Knowing (Oxford: University Press).

Hamlyn, D. W., 1992, Being a Philosopher: The History of a Practice (London: Routledge). Haslanger, S., 2000, 'Gender and Race: (What) Are They? (What) Do We Want Them To Be?', Noûs 34 (1)(2000): 31-55.

Haslanger, S., 2008, 'Changing the Ideology and Culture of Philosophy: Not by Reason (Alone)', Hypatia 23 (2): 210-223.

Marconi, D., 2014, Il mestiere di pensare, (Torino: Einaudi).

Saul, J., 2013, 'Implicit Bias, Stereotype Threat and Women in Philosophy', in Women in Philosophy: What Needs to Change?. eds. F. Jenkins, K. Hutchison (Oxford: Oxford University Press) 39-6o. 
Steele, C. M., 2010, Whistling Vivaldi: How Stereotypes Affect Us and What We Can Do, (New York: W.W. Norton).

Steele, C. M., Aronson, J., 1995, 'Stereotype threat and the intellectual test performance of African Americans', Journal of Personality and Social Psychology (69): 797-811.

Townley, C., 2011, A Defense of Ignorance: Its Value for Knowers and Roles in Feminist and Social Epistemologies (Plymouth: Lexington Books).

Tripodi, V., 2015, 'Intuition, Gender and the Under-representation of Women in Philosophy', Rivista di Estetica (58) (1): 134-144.

Valian, V., 1998, Why so slow? The advancement of women (Cambridge (MA): The M.I.T. Press).

Valian, V., 2005, 'Beyond gender schemas: Improving the advancement of women in academia', Hypatia (20): 198-213.

Witt, C. (2007), 'Feminist History of Philosophy'. In The Stanford Encyclopaedia of Philosophy, ed. E. N. Zalta (URL = http://plato.stanford.edu/entries/feminism-femhist/). Witt, C. (2006), 'Feminist Interpretations of the Philosophical Canon', Signs: Journal of Women in Culture and Society, (31) (2): 537-552. 